\title{
'Moralising' Welfare and Migration in Austerity Britain: A Backdrop to Brexit
}

\begin{abstract}
This article begins by examining UK government discourse on welfare and migration for the period 2010-2016, viewed here as the expression of a distinctive process of moralisation. This discourse is characterised by claims to fairness, responsibility, and austerity, and explicitly sets domestic welfare dependency and migration in opposition to each other. Its operationalisation is traced through a formal mapping of civic stratification in relation to both domestic welfare and freedom of movement within the European Union, while also noting the absence of supporting empirical evidence. The article then looks to the informal aspect of civic stratification, and the role of political discourse in negatively shaping the moral standing of both domestic welfare recipients and EU migrants. Together with the uneven impact of welfare reform, their discursive opposition provides an important amplification of common understandings of the Brexit vote as delivered by the 'left behind' (Goodwin and Heath, 2016).
\end{abstract}

Key words: moralisation, Brexit, civic stratification

\section{Introduction}

The success of the Brexit vote in June 2016 was a surprise to many, not least the then Prime Minister David Cameron, who launched the referendum in an attempt to secure public commitment to membership of the European Union (EU) and resigned in the wake of the result. The present paper aims to provide the contextual background to a particular aspect of the Brexit vote, related to the political discourse of morality as fairness that has underpinned both welfare and migration policy for the Coalition government (2010-15) and its Conservative successor. The research question is therefore twofold: how did a discourse of fairness translate into an attack on an alleged 'dependency culture' within the domestic population; and how did this configuration mesh with a drive to reduce migration and curtail migrant access to benefits, in a manner that fuelled resistance to EU membership? 
The paper proceeds by outlining a discourse of morality and fairness in the speeches of David Cameron, and tracing its operationalisation through related policy changes, notably the aggressive curtailment of welfare rights for both domestic claimants and EU nationals. Combined with an attack on the 'abuse' of free movement (FM), a claimed displacement of British workers, and a policy of deficit reduction, the effect was to place a denigrated and disadvantaged domestic population in a zero-sum relation to EU migration, though the driving rationale was unsupported by available empirical evidence. There are two strands to the analysis to follow: 1) an outline of the discursive content of key political speeches; and 2) the implementation of such discourse in terms of the formal and informal dimensions of civic stratification, a distinction that respectively refers to legal entitlement to rights, and to the related moral standing of affected groups.

These two analytical strands combine to reveal a perverse effect of the discursive and policy package. In setting domestic welfare recipients and migrants groups in opposition, together they provide the context for a strong degree of Brexit support in the deprived areas most affected by welfare reform, but not commonly subject to high levels of inward migration. The closing section of the paper uses this background to amplify a particular understanding of the Brexit result, which Goodwin and Heath (2016:331) argue was 'delivered by the left behind - social groups united by a general sense of insecurity, pessimism and marginalisation' in what Munch (2012) has termed the 'liberal competition state'.

Welfare, migration and morality

More broadly, this paper engages and elaborates themes from related literature on the reconfiguration of welfare, economy and solidarity within a changing global division of labour, underpinned by a distinctive moral construction of economic and social relations. In this context, Munch (2012) characterises the 'liberal competition state' as a turn away from collectivised social inclusion towards individualised forms, such that social provisions are subsumed under strategies of activation and deterrence. He notes that a key issue in this process is who succeeds in the symbolic struggle, and 
while this struggle operates at the level of political rhetoric, it can shape the way that welfare problems are perceived and tackled.

A social insurance system essentially collectivises risk, involving some acceptance of a sense of collective fate, and some recognition of the equal standing of participants - hence Marshall's (1950) conception of citizenship as a confirmation of equal social worth. Mau (2003:45-6) argues that a willingness to share depends on the 'moral persuasiveness' of welfare institutions, but recognises that this is subject to a 'politics of interpretation'. The factors at play in terms of public acceptability are financial contribution, personal desert, and social belonging, raising questions as to what is fair, and who is worthy that have no ready answer, each being amenable to interpretation, manipulation, or persuasion. Hence Lockwood's (1996:536) argument that: 'the ethos and practice of citizenship is at least as likely as class relations to structure group interests and thereby fields of conflict and discontent.'

Migration is clearly part of this picture, and Freeman's (1986) classic article gives a persuasive account of a dynamic whereby the welfare state requires closure because 'it establishes a principle of distributive justice that departs from the distributive principles of the free market' (p52). His argument is that in establishing a guaranteed social minimum welfare requires a moral grounding in fellow feeling, and also provides a baseline for resisting deterioration in the terms and conditions of employment. Foreign workers may offer an alternative to the domestic population as a supply of more tractable labour, but Freeman argues that this will succeed only if they can be excluded from access to welfare rights, or if welfare standards are more generally undermined.

The points at issue are therefore migrants' terms of entry and stay in the host country, the extent of their access to the welfare system, the degree of public acceptance of their presence, the regulation and buoyancy of the labour market, and how far any related erosion of domestic guarantees can be sustained. Many of these factors fall into the realm of political choice and influence, and the way that politicians may seek to embed welfare and migration within a refashioned moral vision thus constitutes a site of contention. Unresolved questions remain concerning the unit of membership and 
belonging (Beitz, 1983), who is included in the 'community of value' (Anderson, 2013), and where does any related gain or loss fall - though EU law to date has largely protected the welfare rights of EEA workers. As Deckard and Heslin (2016) note, there is now a significant population whose identities transcend national borders, and who exist alongside the deteriorating status of (lower class) citizens within their home nations.

While debate has traditionally been framed in terms of the impact of migration on the welfare state (eg. Freeman, 1986), Geddes (2003) reverses the question. He argues that not only do resource pressures require a tightly defined community of membership with respect to welfare entitlement, but that entitlement itself is increasingly viewed in relation to immigration control. This relationship is driven by fears of a 'pull factor', such that policies to minimise welfare inclusion serve to enhance the possibilities for deterrence, monitoring and control. A crucial element is the classification of migrants by their grounds for entry (Morris, 1998; Sainsbury, 2012) and hence by immigration status, and the related specification of inclusions and exclusions with respect to welfare support. Marshall's focus on social inclusion is thus reversed as welfare rules become part of a filtering system linked to the sorting of migrants by criteria of worth.

Analysis in this mode has been advanced by the application of Lockwood's (1996) concept of 'civic stratification', a system for the differential granting of rights shaped by underpinning judgements of merit or dis-merit, respectively referring to formal entitlement, and what might be termed informal 'moral standing'. While Lockwood's original argument was principally concerned with the inequalities generated within citizenship, most notably through the construction of welfare dependents as a group 'lacking in civic virtue' (p.539), its application has been extended to include a consideration of migrant rights (Morris, 1997, 2002; Kofman, 2002). The concept is deployed in the present study to address within one frame both how citizenship is internally stratified by the measures of discipline and control that accompany welfare claims, and how migrants are stratified by their basis of entry and the associated granting or denial of rights. In each area formal legal standing and informal judgements of merit are shown to be in play, and in this vein Anderson (2013) notes that 
laws on citizenship, welfare and migration create rather than reflect differential status positions. Together, she argues, they represent a set of social, economic and political relations that say much about how we make sense of ourselves.

A number of writers (Booth, 1994; Sayer, 2007; Clarke and Newman, 2012) have addressed such dynamics by reformulating the notion of 'moral economy'. Originally rooted in analysis of Britain's $18^{\text {th }}$ century food riots (Thompson, 1971), this concept has been given contemporary relevance by the argument that all economies are moral economies, implying and depending upon a supporting moral frame. Attention has therefore turned to the production of moral sentiment in shaping socio-economic practice (Fassin, 2009; Sayer, 2007), and to the way that publicly circulated moral meanings offer a basis for generating and justifying social classification (Hitlin and Vaisey, 2013). Nowhere is this more apparent than in the fields of welfare and migration, where economic and moral distinctions become difficult to separate. The present paper therefore looks to the question of how social norms become the site of political intervention, and how such intervention is made apparent in political discourse, in the design and operation of a given policy domain, and in the shaping of public sentiment.

Key questions in this exercise are how legitimacy and desert are defined with respect to welfare entitlement, and how far national sovereignty extends in this matter, issues highlighted by Britain's assault on the welfare rights of EEA workers. While post-national migration has been linked to the erosion of national sovereignty and the assertion of universal rights, inclusion within the welfare community is carefully constrained and can provoke resistance from the domestic population, some of whom are themselves confined to the margins of their own society. Such tensions have been apparent in Britain for some time (Duevell and Jordan, 2002), but acquired particular significance in the run-up to the referendum on EU membership, as David Cameron sought to reform but remain in the EU. For a further understanding of their nature and effects, we can look to the political discourse underpinning the configuration of welfare and migration embraced by the 2010 Coalition government and its Conservative successor, and the associated impact on the moral standing of its target groups. 
The present analysis of political discourse in this period was based on David Cameron's party conference speeches, together with his more targeted welfare and immigration speeches -24 in all. These texts are supplemented by cross-reference to speeches from the then Minister for Work and Pensions (Iain Duncan Smith), and the then Immigration Minister (Damien Green). All are listed in the appendix to this paper.

Analysis of the associated discourse was informed by Freeden's (1996; 2003) approach to mapping ideology, whereby 'social truths' depend upon the translation of abstract concepts into substantive content. Ideology in this context is viewed as a recurrent pattern of beliefs and values dedicated to (re)ordering the social world, and given expression through the communicative devices of political discourse. This framework directs attention to how contestable political concepts (such as morality) are given concrete substance or 'decontested' in key political statements. Associated analysis will therefore rest on the identification of 'core' concepts that are central to a given position, and the way their substantive content is provided by closely related (adjacent) concepts that flesh out their meaning - as with morality, fairness and responsibility. These in turn are amplified by more loosely linked 'peripheral' concepts that are used to give further background support.

Examples are provided below, though in practice this process of translation does not operate exclusively at the conceptual level, but rather moves from greater to lesser degrees of abstraction. In fact, as a supplement to analysis, the resultant discourse can also be linked to social groups or behaviour patterns that serve as reference points for its key elements, and can be grouped in terms of related mutual affinities or oppositions. This is what Laclau (2014:68) terms the logic of equivalence and difference, or the construction of 'equivalential chains'. We see below how such chains are made up of linked concepts and behaviours, and can be used to show how a discourse has the potential to unite or divide social groups according to their standing in relation to the key issues in play. 
For the present paper, a thematic analysis of all the then Prime Minister's speeches noted above was conducted to identify recurrent themes, and their core concepts, substantive (adjacent) content and more loosely associated (peripheral) content. Analysis in this mode is an interpretive rather than a mechanical exercise, and as in Freeden's account requires a hierarchical approach that begins by identifying dominant concepts, and tracing their substantive content through threads of meaning and association. 'Fairness' stands out as a recurrent theme, appearing in a large majority of Cameron's speeches, often allied with 'morality' and closely associated with responsibility. Thus, texts must also be read for proxy concepts or phrases that act together with or substitute for dominant concepts, and serve to frame more detailed references to specific policy issues. As we see below, addressing 'the moral hazard of welfare', tackling the 'something for nothing culture', linking 'what you pay in to what you get out', and ending 'abuse' of FM, all stand for 'fairness'. Readings must therefore identify not just a recurrent vocabulary, but also recurrent meanings, which then permit a line to be drawn from abstract principles, to substantive content, and to promised policy change. A further step may look towards target audiences and implicit oppositions, often clearly signalled in political speeches as with 'hardworking British taxpayers' (Cameron, 2014b), or more vaguely 'putting British people first' (Cameron, 2014).

\section{Analysing the discourse}

The analysis of discourse below proceeds chronologically, citing indicative statements that reveal an emergent pattern of meaning in Cameron's key speeches. Thus, his pre-election 'Age of Austerity' speech (Cameron, 2009) announced a reshaping of Britain on the basis of responsibility, followed by a stated desire to 'change the way we think about ourselves and our role in society' (Cameron, 2010). These objectives were linked in 2010 and 2011 to an expanded notion of fairness, which was aimed not just at who gets help but 'who gives that help through their taxes' (Cameron, 2010), such that 'real fairness...is about the link between what you put in and what you get out' (Cameron, 2011). By the 2012 Conservative Party Conference, Cameron had announced the related programme of welfare reform as a 'moral mission', in which 'unfairness' had become his first 'great evil' (Cameron, 2012, 
see also 2014). An unfolding narrative now becomes apparent. In Freeden's terms, morality emerges as a core concept, closely associated with the adjacent concept of fairness, contrasted with personal irresponsibility and social profligacy, and peripherally linked to an overriding drive for deficit reduction and a pledge to address the 'something for nothing culture' (Cameron, 2012a; DuncanSmith, 2013). The lines of equivalence and difference are thus drawn to associate unfairness with profligacy, dependency, and welfare recipients (both in-work and out-of-work), as set against austerity, responsibility, and hardworking taxpayers.

However, the same set of speeches drawn on above contains a further opposition, one that offers in some respects to redeem the welfare recipient, and that is the opposition between migrants and the British people. By the time of Cameron's 2011 conference speech immigration had become part of the welfare picture, and the economy inherited from New Labour was argued to have left 'a welfare system that trapped millions in dependency (and) an immigration system that brought in migrant workers to do the jobs that those on welfare were being paid not to do.' (Cameron, 2011; see also 2013). So breaking the 'cycle of dependency' meant 'sorting out welfare and immigration', which in turn meant capping net migration. The theme was repeated in other speeches, hence: 'Welfare and immigration are two sides of the same coin...we will never control immigration properly until we tackle welfare dependency' (Cameron, 2011a; see also Duncan-Smith, 2011¹).

The language deployed in relation to welfare reappears, but 'fairness' is turned to address the position of 'British born people stuck on welfare' (Cameron, 2011a), British people affected by illegal migration (Cameron, 2011a), communities under pressure on schools, housing ${ }^{2}$ and health care (Cameron, 2011a; Cameron, 2013a); and immigration that damages the labour market and pushes down wages (Cameron 2015). We also learn of a 'hard-working British public' concerned about migrant exploitation of services and benefits ${ }^{3}$. In these scenarios, the 'fairness' challenge to migrants is about making sure 'you put into Britain you don't just take out', while the 'fairness' challenge for policy is again about protecting the British taxpayer. (Cameron, 2013a; 2014b). 
An early focus (Cameron, 2011a; Green, 2010) was on capping non-EEA migration and 'closing a loophole that allows illegals to claim benefits'4. However, attention soon turned to FM within the EU, and softening statements about the benefits of migration were counter-posed by 'fairness' as the need to end the 'something for nothing culture' among migrants. Making the case for Remain therefore entailed a refusal to 'go on endlessly paying' (Cameron, 2013a), assertions that no-one could come and expect benefits on arrival (Cameron, 2013b, 2014b), a promise to limit the stay of jobless EU migrants, and a commitment to deal with the 'abuse of free movement' (Cameron, 2014b; 2015a) and 'rogue' EU benefit claims. ${ }^{5}$ Combined with the aim of restricting access to in-work supplements (currently termed Tax Credits), it was argued that this would 'reduce the incentive for lower paid, low skilled EU workers to come here in the first place' (Cameron, 2014b).

One interesting aspect of this linkage between migration and welfare is that it places domestic welfare recipients in an ambiguous position; condemned by the 'responsibility and fairness' agenda they are now able to perceive themselves as subject to unfair treatment. In the name of deficit reduction, they are exposed to heightened conditionality, capped benefits, and frozen rates, variously applying both to out-of-work and in-work benefits ${ }^{6}$. This welfare austerity is then accompanied by references to immediate and 'indefinite' benefit payments for EU nationals, the contested claim ${ }^{7}$ of a 40 per cent rate of welfare dependency among recent arrivals (Cameron, 2015a), and assertions that immigration has trapped British people on benefits and driven down wages. The contours of equivalence and difference may now be reconfigured. British welfare recipients can potentially align themselves with fairness and responsibility, against the 'abuse' and unfairness that allegedly causes their dependency, to take up a position more closely allied to a legitimate claim for recognition and protection.

\section{Operationalising the discourse}

The translation of rhetoric into policy can be viewed through the lens of civic stratification, and Lockwood see sees a vital role for welfare policy in both the structuring and legitimation of inequalities. In terms of the discourse above we can therefore ask how espoused principles of fairness and responsibility are made manifest in the details of policy change from 2010 onwards. The resultant 
measures are presented below in terms of their stratifying effects on formal entitlement, while the informal dimension of civic stratification is more fully addressed in a later section.

\section{$\underline{\text { Domestic welfare }}$}

Although the translation of discourse into policy is not necessarily automatic or transparent, the discursive attack on dependency culture explicitly prepared the ground for a radical reform of the welfare system, via the 2012 Welfare Reform Act, and the 2016 Welfare Reform and Work Act. Related policy documents both anticipate and echo the speeches cited above, and prior to the 2010 election, the Conservative Party (2008), announced its 'responsibilities agenda', to proclaim that 'ending Britain's welfare culture is a moral duty'. This aim was repeated in a Consultation Paper preparatory to the 2012 Act (Department of Work and Pensions (DWP), 2010), foregrounding tighter conditions for unemployed claimants, while the Universal Credit system currently unfolding (DWP, 2010a) extends conditions to people in receipt of low wage supplements.

The reforms began to take effect well in advance of the referendum, and continue to unfold into the present, with a radical restructuring underway to deliver an integrated Universal Credit (UC) ${ }^{8}$ system of working age benefits. Its aims are to promote responsible behaviour, establish 'fairness' between givers and receivers, and impose tighter conditions on all claimants, both in and out of work (DWP, 2010a). The policy aims are directed towards the need to accommodate a 'modern flexible economy' (Duncan-Smith 2014), which has seen a marked increase in zero hours contracts and false selfemployment (TUC, 2016).

Such developments have been viewed as a shift in the foundations of good citizenship such that responsibility for social cohesion and integration falls on the individual (Soysal, 2012), but this should not blind us to their stratifying effects. Thus, Munch (2012:251) notes that one result of such individualised orientation is to produce 'a lower class that feels no longer cared for in the national community', a key referent in explanations of the Brexit vote (Goodwin and Heath, 2016). The welfare reforms to date ${ }^{9}$ have disproportionately affected social groups that already occupy a 
vulnerable class position, exposing them to reduced subsistence income and punitive sanctions (JRF, 2014). They have an additional stratifying effect in highlighting a negative status position of dependency, extended under UC to include receipt of low-wage supplements, while imposing a cumulative disciplinary regime on claimants through the detail of policy design and implementation.

Welfare eligibility in Britain does not require a contribution record, but over the period 2010 to the present, has increasingly engaged moves towards greatly enhanced conditions for the unemployed that intensify with the duration of a claim ${ }^{10}$, and carry incremental sanctions for failure to comply (Webster, 2015). In the name of deficit reduction, all working age benefits have been frozen for four years from April $2016^{11}$, following earlier differential freezes and limits on up-ratings, a monetary cap has been placed on total household benefit income, and various cuts imposed on Housing Benefit and Council Tax Benefit. A further stratum of change has been directed at support for the low paid, reducing the earnings allowed before triggering a benefit reduction, while conditionality for the new UC will compel low earners to seek more hours or better pay. 'Activation' policies have also been heightened for disabled claimants deemed capable of work, and for lone parents.

One further stratifying effect has been geographical. Vastly uneven cuts to local authority spending over the period 2010 to 2015 have meant an average fall of 23.4 per cent per person, rising to over 45 per cent in the hardest hit authorities (Becker et al, 2016; Crewe, 2016). These cuts have directly affected some benefits, while also falling most strongly on areas of pre-existing deprivation.

\section{EEA nationals and benefit entitlement}

While all migrants acquire full social rights on achieving permanent residence, stratifying techniques of control have long been deployed to cover the intervening period. From 2010 onwards (Gower, 2015) non-EEA migration has increasingly been managed by income and skill thresholds, as well as pre-existing welfare exclusions, but this left EEA nationals who were exercising freedom of movement under Directive 2004/38/EC and who had stabilised at around half of all trans-national migrants. Under this Directive, EEA workers and jobseekers are entitled to equal treatment in relation 
to benefits facilitating access to the labour market, but the UK government has sought to deter their presence by stratified devices of control that make the fullest use of permitted restrictions. Here we see a direct link between discourse and policy, in an elaboration of the fairness and responsibilities agenda designed to target FM of workers within the EU.

Britain had already imposed transitional restrictions on labour market and benefit access for Bulgarian and Romanian (A2) workers for the maximum permitted period of seven years, and in 2013 David Cameron turned public attention to the alleged 'abuse' of FM, with the A2 restrictions due to end later that year. The ensuing measures to limit out-of-work benefits for EEA nationals were rushed through in regulations governing their access, effective from January 2014, and announced in Press releases that quote directly from Cameron's speeches. They purported to reduce 'the magnetic pull of Britain's benefit system, ${ }^{12}$ and to address the concerns of 'the hardworking British public' ${ }^{13}$ (Cameron, 2014a) - many of whom were themselves subject to austerity measures aimed at deficit reduction.

When Cameron promised that 'no one can come to this country and expect to get out-of-work benefits immediately...(that) we will no longer pay these indefinitely', and that FM 'cannot be completely unqualified' (Cameron, 2013a) he was clearly referring to EEA workers. This partly reflects a concern about the non-contributory nature of most benefits, which is a feature of the UK system itself. In fact, FM within the EU has never been entirely unconditional, ${ }^{14}$ but recent UK policy has strained at the boundary of what is permissible (O’Brien, 2015) with a view to limiting access to benefits, deterring arrivals, and addressing the so-called 'abuse' of FM (Cameron, 2014b). However, while the measures introduced were intended to reassure the 'British public', they equally served to highlight an alleged 'problem' that could be ameliorated but not eradicated while Britain remained in the EU.

Targeting EEA job-search, key measures (Kennedy, 2015) included a requirement of 3 months prior residence for jobseekers allowance (JSA - unemployment benefit), and its extension to Child Benefit and Child Tax Credits. From January 2014 onwards $^{15}$ there was a statutory six month limit on JSA claims by new EEA jobseekers and previous (retained) workers, later reduced to three months for jobseekers. A genuine prospect of work test is applied to the latter group after three months, and for 
retained workers after six months, while failure means a loss of the right to reside that in turn rebounds on the path to permanent residence. A minimum earnings threshold has been introduced to the designation of worker status, new jobseekers have been excluded from eligibility for Housing Benefit, and in March 2015 Parliament passed regulations to exclude EEA jobseekers from eligibility for UC.

These widely publicised measures ${ }^{16}$ were designed to limit migrant access to benefits and discourage EEA migration to Britain, but in practice focused attention on a 'problem' that scarcely existed. Thus, Favell (2014:286) notes 'the government's inability to marshal any evidence in support of its own official position', and observes that such anti-EU argument is emotional and not empirical.

\section{Rhetoric or reality?}

It is therefore important to consider how far the world view constructed by political discourse and advanced by associated policy measures addressed an actually existing problem, supported by empirical evidence. The discourse and policy package outlined thus far rests on two (somewhat conflicting) claims - that domestic welfare dependency is in part attributable to the presence of migrant workers; and that EEA migrants are drawn to Britain by the availability of welfare benefits, and are thus a drain on resources. In fact, data from official sources support neither claim, and the Office for Budget Responsibility (OBR, 2013, Annex A) notes that the main effect of a rise in net migration is to increase labour supply, bring higher returns on capital, increase investment, and improve the debt to GDP ratio.

A variety of studies (eg. Lemos and Portes, 2008; Migration Advisory Committee (MAC), 2014; Ruhs and Vargas-Silva, 2015) show only minimal displacement of British workers, and even confining attention to low skilled migrants, the Chair of the government's MAC (Metcalf, 2016, section 6) concluded: '(they) have a neutral impact on UK-born employment rates, fiscal contribution, GDP per head and productivity'. The MAC (2014) also reports only slight downward pressure on wages for UK born workers in semi/unskilled work (cf. Devlin et al, 2014), calculated by Portes to amount to 1 
per cent over 8 years ${ }^{17}$, not least because of protection offered by minimum wage legislation. Against this background, the MAC crucially registers a need to address the gap between public perceptions and reality, which they argue can lead to poor policy choices.

So if EEA migrants were not displacing British workers, were they excessively dependent on welfare benefits? In fact, available data does not come close to supporting the political discourse. In the year before restrictions were imposed, EU migrants accounted for 4 per cent of all JSA claims, and 2.1 per cent of all working age benefit claims ${ }^{18}$ (Keen and Turner, 2016), while making up 4.8 per cent of the workforce $^{19}$. Though Tax Credit receipt for EU migrants is proportionately higher than for British workers, at 14 per cent as compared with 11 per cent (Keen and Turner, 2016), official figures show that EU arrivals over the four years to 2016 paid $£ 2.54$ bn more in income tax and National Insurance than they received in Tax Credits or Child Benefit. ${ }^{20}$ Yet urgent measures rushed through to address the 'problem' of benefit tourism inevitably foster the opposite impression, undermining the 'moral standing' of the target group, and with it support for EU membership.

\section{Moral standing}

We have seen above how civic stratification can operate through formal status distinctions that govern both welfare eligibility for the domestic population, and conditions of entry and stay for migrants.

However, the management of public perceptions and sentiment accompanying patterns of entitlement will in turn operate through informal distinctions of desert, underpinned by what we might term moral standing in society. Indeed, in addition to the construction of formal statuses determining differential access to rights, Lockwood's (1996) schema points to the role of 'moral and material resources' in both the legitimation and effects of civic stratification. Moral resources refer to 'advantages conferred by social standing and social networks', and most crucially for the present argument 'the ability to attain one's ends through the activation of shared moral sentiments' (p36).

The influence of moral resources in Lockwood's account serves as a vehicle for civic expansion through claims for enhanced treatment in the delivery of rights, or mobilisations for the creation of 
new rights, but he neglects to consider the reverse dynamic of contraction. Attributions of blame, allegations of abuse, and a questioning of desert, all negatively affect perceptions of legitimacy and thereby moral standing, and we have seen this process at work in political discourse addressing both domestic welfare claims, and the rights of FM in Europe. This discourse and related policy measures then feed public perceptions that radically misjudge the scale of the 'problems' in question. ${ }^{21}$ In fact, the discourse and policy designed to limit social rights - whether through enhanced conditionality for domestic claimants, or the campaign against benefit tourism from the EU - are a more plausible source of any related 'moral panic" 22 than substantial evidence of abuse or significant resource drain. The effect has been to present EU migrants as competitors in a struggle over shrinking resources, rather than as net contributors who are the latest target of a shift in the nature and purpose of welfare protection. Their legitimacy and desert are thus placed in question and their moral standing impaired.

Lockwood argues that institutional structures for delivering the rights that are central to social integration may also affect class formation (or class de-formation), and political discourse has not only condemned domestic welfare claimants and EU migrants, but has set them against each other. Within an increasingly 'flexible' labour market (Inman, 2016; Forsey and Field, 2016) we have seen enhanced welfare conditionality and sanctions for both out-of-work and in-work benefits, accompanied by discursive oppositions between welfare dependents, migrants, and hardworking taxpayers, and supplemented by accusations of benefit tourism and abuse of FM. Thus, for both domestic welfare recipients and EEA migrants an attack on moral standing by means of political rhetoric has been a prelude to increased conditionality in the delivery or denial of rights, while also fuelling the scope for resentment towards the latter group.

Government rhetoric on migration and benefits has been misleading with respect to both the level of claims and their likely duration, and several bodies note the lack of supporting data (MAC, 2014; NIESR, 2015 ${ }^{23}$; House of Lords written question HL4654), or even significant labour market displacement (Devlin et al, 2014). Indeed, the Council of Europe ${ }^{24}$ has highlighted the need for a more nuanced and evidence based public narrative on these issues, while Wadsworth (2015) observes that 
the key significance of immigration lies less in its empirical effects than in its impact on public perceptions. But as Munch has observed, it is the rhetoric itself that shapes the way problems are perceived and tackled, and in this context, the promise of phased-in access to Tax Credits for new arrivals - the most relevant aspect of Cameron's EU negotiations - looked ineffectual. Given the government discourse on domestic welfare, migration, and benefit tourism, Britain's attempt to secure concessions on FM - themselves constrained by EU law, served to confirm these problems in the public eye and further erode the moral standing of EU migrants.

Questions could be raised about the extent to which migrants and domestic welfare claimants might make common cause (Migrant Rights Network; ${ }^{25}$ Metcalf, 2016) - non-standard workers gain from EU level employment protection (JRF, 2016), and a number of 'cross-over' issues affect the two groups. Both have been exposed to exploitation in a 'flexible' and poorly regulated labour market (MAC, 2014, Metcalf, 2016; Field and Forsey, 2016); both are affected by austerity measures in the operation of the welfare system; both experience increased conditionality and surveillance in accessing their rights; and both groups suffer from the erosion of public services associated with reductions in local authority funding (Crewe, 2016). However, one key to understanding public perceptions must be the political construction of a world view based on a vision of limited good, whereby the presence and rights of migrants detract from the resources and opportunities available to the domestic population.

\section{Reflections on the Brexit vote}

The results of the referendum are well known. Leave succeeded on 51.9 per cent of the $\operatorname{vote}^{26}($ Becker et al, 2016), based on a broad coalition of three different groups - Eurosceptics ( 23 per cent of the population, 75 per cent voting leave), the older working class (16 per cent of the population, 73 per cent voting leave), and an economically deprived anti-immigrant group (12 per cent of the population, 95 per cent voting leave) (Swales et al, 2016). The Leave vote was in practice multi-faceted, but much attention has focussed on low income and low skilled groups living in deprived areas - the 'left behind' (eg. Goodwin and Heath, 2016; Sensier and Devine, 2017), in part because these 
circumstances make for unstable sentiments, open to persuasion from differing political positions (Munch, 2012:251). For these voters, the backdrop to the result was arguably sketched out in Cameron's discourse on welfare and migration, and their mutual associations.

The referendum happened in the context of an austerity drive geared to deficit reduction, a government discourse condemning EU migrants' indefinite and immediate benefit entitlement, increased precarity of employment (Field and Forsey, 2016), and a lack of wage growth at the lower levels (Allen and Elliott, 2016). While the most direct link in the discourse was made between unemployment and migration, British workers facing insecurity, cuts to Tax Credits, and attacks on dependency would also be vulnerable to an argument that foregrounded 'fairness' but left them precariously placed. Aggregate summaries of the vote and analysis at local authority level all paint the same picture, with low income a key predictor of the Leave vote (Goodwin and Heath, 2016), together with a sense of worsening personal circumstances relative to others (Swales, 2016), especially notable given benefit cuts and freezes. At highly disaggregated ward level ${ }^{27}$ deprivation correlated strongly with support for Leave, which was also characterised by high unemployment, low income, and a traditional reliance on manufacturing (Becker et al, 2016; Beatty and Fothergill, 2016).

Becker et al (2016) stress the multi-causal nature of the result, arguing that explanatory power will come only from understanding on a variety of dimensions, and this is apparent in a delicate balance between value based and resource based factors in proffered accounts. While documenting and endorsing the socio-economic correlations noted above, Goodwin and Heath (2016) point to a preexisting value conflict that underpinned earlier growth in support for the UK Independence Party. In this scenario, political and media elites espouse support for social liberalism, multi-culturalism and EU membership, while left-behind social groups are united by a more nativist response to perceived threats of rapid social and cultural change. Goodwin and Heath (2016:31) then argue that as a result these groups have 'long felt excluded from the mainstream consensus and used the referendum to voice their distinctive views.' 
Becker et al (2016) similarly stress the explanatory power of what they term 'political' factors ${ }^{28}$, but also point to the uneven burden of fiscal consolidation to argue that the referendum result was at least partially related to distributional issues. Indeed, a mapping of the vote confirms that cuts to both welfare and local authority funding, each strongly associated with entrenched deprivation (Beatty and Fothergill, 2016; Becker et al, 2016), correlate closely with support for Leave. By 2015, the areas worst hit by benefit cuts were losing four times as much per year per working age adult as the least affected, and were typically older industrial areas and deprived seaside towns (Beatty and Fothergill, 2016) - precisely the terrain of support for Leave. Becker et al (2016) additionally point to local authority spending cuts (which also affect some benefits), and found that authorities experiencing a higher level of cuts were more likely to favour Leave, in part because the geographical pattern of loss coincides with other pre-existing deprivations. They observe that voters may have inadvertently weighed the cost of EU membership against the sizeable extent of domestic welfare and benefits cuts, and turned away - a response endorsed by resigned cabinet minister Iain Duncan-Smith (2016).

Fiscal consolidation and entrenched disadvantage thus provide the context for what Goodwin and Heath term a values conflict, and together they help to make sense of one superficially surprising aspect of the referendum results. Swales et al (2016) found concern about immigration levels to be the biggest single factor distinguishing Leave and Remain supporters, though in fact areas with the highest level of migration expressed least concern and tended to favour Remain, while the strongest Leave areas were generally those with the smallest migrant populations. ${ }^{29}$ Goodwin and Heath (2016), however, found that it is the rate of change that affected people's vote, a rapid rate being associated with Leave - even at low overall levels of migrant presence. This specifically applies to the inflow of East European migrants over the last ten years, a group of migrants who are more geographically dispersed than previous arrivals, ${ }^{30}$ and Becker et al (2016) note a likely interaction effect when an increased flow of lower skilled migrants into a disadvantaged local population coincides with exposure to welfare reform and spending cuts. 
While this offers a recipe for strong Leave support, we should also look to the political environment in which these effects operate ${ }^{31}$ and attention to this background can amplify aggregate analysis of voting patterns of the 'left behind' to provide a more dynamic understanding of their position. In fact, the circumstances favouring support for Leave were significantly enhanced by the policies and discourse promoted by David Cameron from 2010 onwards, such that his aim to "change the way we think about ourselves' militated against his Remain agenda. We have seen a condemnation of dependency in the domestic population (for both in-work and out-of-work benefits), heightened cuts and conditionality in their benefits, a claimed association between welfare dependency and migration, and unfounded assertions about the abuse of FM and benefit tourism. In sum, a section of the domestic population whose moral resources are weak and whose moral standing has been systematically impugned, have seen their welfare rights eroded and their living standards fall, and have classically been offered a target to blame - albeit one that flies in the face of empirical evidence.

\section{The 'just about managing'}

When Theresa May assumed the position of Prime Minister she seemed to speak directly to the concerns of the 'left behind', announcing a mission to make Britain 'a country that works for everyone' (May, 2016), and promising to deliver a society with 'fairness and solidarity at its heart' (May, 2017). She appealed in particular to people 'working around the clock' and only 'just about managing' (JAMs), but a close reading of her early speeches (see appendix) shows more consistency with the Cameron discourse than at first appears. Her 'Shared Society' speech (May, 2017) acknowledged a need to support the vulnerable, but the focus was her promise 'to help those who have been ignored by the government for too long because they don't fall into the income bracket that makes them qualify for welfare support'. Thus, while there was no overt attack on dependency culture, the old dividing lines remain in place - as do the benefit cuts and freezes.

In fact, cuts currently unfolding particularly affect supplements for the low paid and for families with children $^{32}$ and raise questions about who exactly are the JAMs. However, fairness is again a rallying cry for those 'out of work or on lower wages because of low-skilled migration' (May, 2016a), and so 
too is the 'injustice' experienced by those 'who see others prospering while (they) are not' and whose 'very identity' is under threat (May, 2017). 'Brexit means Brexit' (May, 2016a) promises them a reclamation of sovereign independence, a rejection of half-way-house measures, and a resumption of control over immigration. However, with frozen benefits, stagnant wages, a falling pound, and rising inflation $^{33}$ - plus eventual loss of EU funds, many seem set to be disappointed, especially in the Brexit voting areas of economic disadvantage ${ }^{34}$.

\section{Conclusion}

This article began by viewing government speeches for the period 2010-16 as the expression of a moralising discourse rooted in conceptions of fairness, responsibility and protection for the hardworking taxpayer. Such discourse has been the basis for an erosion of social rights through increased conditionality and deteriorating living standards, while its extension from welfare to migration has placed domestic welfare recipients in an ambiguous position. Condemned for their own dependency, they have nevertheless been deemed unfairly subject to the impacts of migration. Although available empirical evidence is far from supporting the discursive claims and policy changes that came to focus on the position of EU migrants, it is argued here that the Brexit vote is at least in part the outcome of a zero-sum vision that sets domestic welfare recipients (in and out of work) and EU migrants in opposition.

While the Brexit process is by its nature unique, it illustrates several points of general interest, not least in offering a particular case study of what has been termed the liberal competition state, and the shifting contours of welfare, economy and solidarity within a changing global division of labour. The account above thus documents the reconfiguration of welfare in a country retreating from the Marshallian ideal of social inclusion while increasingly reluctant to embrace the construction of a post-national Europe. In so doing it documents an instance of the turn away from collectivised protection to individualised activation and deterrence, respectively targeting domestic welfare dependency and freedom of movement within the EU. 
The study provides an illustration of the significance of what Munch (2012) terms the symbolic struggle in relation to welfare, economy and migration, showing the importance of political rhetoric in constructing the potential for affinities and divisions both within the domestic population, and between the 'left behind' and in-coming migrants. In constructing this account, it has been argued that an understanding of the dynamic in play could be further advanced by the concept of civic stratification. This concept is used here to extend a purely discursive approach by both tracing the formal translation from discourse to policy, and outlining a subsequent informal impact on the moral standing of its targets. The absence of evidence to support key elements of the policy is significant, and illustrates the role of discourse in creating the appearance of a problem to be solved - in this case the welfare/migration configuration. While the Brexit vote has sometimes been understood as a value conflict between the 'left behind' and a more distant liberal elite (Goodwin and Heath, 2016), that conflict was actively fuelled by a discourse and policy intended to shore up support for Remain. The outcome thus stands as a perverse effect of so forcefully pitting FM in Europe against the interests of domestic welfare recipients, in a bid to reform but remain in the EU.

Though Brexit stands as a peculiarly British phenomenon, the analysis offered here presents some points that could prove relevant for other Member States. It illustrates the political volatility that can emerge when internal inequality, falling living standards, identity, and sovereignty are in play, and when immigration is perceived or presented as a crisis issue. A popular call for national policies that speak to these concerns potentially undermines the scope for cohesion at EU level, and the whole combination is ripe for exploitation by appeal to a national group or groups who feel that their interests are not well represented. The account above points to the ease with which political discourse can over-ride empirical data, the significance of political rhetoric in shaping the way problems are perceived and tackled (cf. Munch, 2012), and the ready availability of migrants as a focal point for discontent. One especially notable feature of the British story for other Member States is the way a desire to address perceptions of national discontent displaced any more positively framed case to Remain in the EU, and instead drove an active retreat from some of its core principles. 


\section{References}

Allen, K and Elliott, L (2016) 'Britain at bottom of league as real wages decline by 10\%', Guardian, 27 July

Anderson, B. (2013) Us and Them, Oxford: Oxford University Press

Beatty, C. and Fothergill, S. (2016) The Uneven Impact of Welfare Reform, Sheffield: Sheffield Hallam, CRESR

Becker, S.O., Fetzer, T. And Novy, D. (2016) Who Voted for Brexit, Warwick: Centre for Competitive Advantage in the Global Economy, Working Paper 305

Beitz, C.R. (1983) 'Cosmopolitan ideals and national sentiment', Journal of Philosophy 80(10):591600

Booth, W.J. (1994) 'On the idea of the moral economy', American Political Science Review $88(3): 653-67$.

Clarke, J. and Newman, J. (2012) 'The alchemy of austerity', Critical Social Policy 32(3):299-319 Conservative Party (2008) Work for Welfare, Consultation Paper

Crewe, T. (2016) 'The strange death of municipal England', London Review of Books, 15 December Deckard, N.D. and Heslin, A. (2016) 'After post-national citizenship', Sociology Compass 10(4) 294305

Devlin, C. Bolt, O., Patel, D., Harding, D. And Hussain, I. (2014) Impact of Migration on UK Native Employment, London: Home Office/Department for Business Innovation and Skills, Occasional Paper 109

Duevell, F. and Jordan, B. (2002) 'Immigration, asylum and welfare', Critical Social Policy 22(3):498-517

DWP (2010), $21^{\text {st }}$ Century Welfare, Cm 7971.

DWP (2010a), Universal Credit: Welfare that Works, Cm 7957.

Fassin, D. (2009) 'Moral economies revisited', Annales. Histoire, Sciences Sociales 64(6):1237-66

Favell, A. (2014) 'The fourth freedom', European Journal of Social Theory 17(3):275-87 
Field, F. and Forsey, A. (2016)

http://www.frankfield.co.uk/upload/docs/Wild\%20West\%20Workplace.pdf

Freeden, M. 1996 Ideologies and Political Theory, Oxford: OUP.

Freeden, M. 2003 Ideology: A Very Short Introduction, Oxford: OUP.

Freeman, G. (1986) 'Migration and the political economy of the welfare state', Annals of the

American Academy of Political and Social Science 534 July:17-30

Geddes, A. (2003) 'Migration and the welfare state in Europe', The Political Quarterly 74(1):150-62

Goodwin, M. and Heath, D. (2016) 'The 2016 Referendum, Brexit and the Left Behind', The Political Quarterly 87(3) 323-32

Gower, M. (2015) Immigration and Asylum: changes made by the Coalition Government 2010-15, London: House of Commons Library, SN/HA/5829

Hitlin, S. and Vaisey, S. (2013) 'The new sociology of morality', Annual Review of Sociology 39:5168.

Inman, P. (2016) 'Flexibility is the new injustice inflicted on the working class', Observer, 22 May JRF (2014) Welfare Sanctions and Conditionality in the UK, York: Joseph Rowntree Foundation Keen, R. and Turner, R. (2016) Statistics on Migrants and Benefits, London: House of Commons Library, BP 7445

Kennedy, S. (2015) Measures to Limit Migrants' Access to Benefits, London: House of Commons Library, BP 06889

Kofman, E. (2002) 'Contemporary European migrations, civic stratification and citizenship, Political Geography 21(8):1035-54

Laclau, E. (2014) The Rhetorical Foundations of Society, London: Verso.

Lemos, S. and Portes, J. (2008) New Labour? The Impact of Labour from Central and European

Countries on the UK Labour Market, Bonn: IZA, Discussion Paper 3756

Lockwood, D. (1996) 'Civic integration and class formation', British Journal of Sociology 47(3):53150

MAC (2014) Migrants in Low-skilled Work, London: Home Office

Marshall, T.H. (1950) Citizenship and Social Class, Cambridge: Cambridge University Press 
Mau, S. (2003) The Moral Economy of Welfare States, London: Routledge

Metcalf, D. (2016) Work, Immigration and the Labour Market, London: LSE

Morris, L.D. (1997) ‘A cluster of contradictions’, Sociology 31(2):241-59

Morris, L.D. (1998) 'Governing at a distance', International Migration Review 32(4):949-73

Morris, L.D. (2002) Managing Migration, London: Routledge

Munch, R (2012) Inclusion and Exclusion in the Liberal Competition State, London: Routledge

O'Brien, C. 'The pillory, the precipice and the slippery slope', Journal of Social Welfare and Family

Law 37(1):111-36

OBR (2013) Fiscal Sustainability Report, London: HMSO

Ruhs, M. and Vargas-Silva, C. (2015) The Labour Market Effects of Immigration, Oxford: Migration Observatory

Sainsbury, D. (2012) Welfare States and Immigrant Rights, Oxford: Oxford University Press

Sayer, A. (2007) 'Moral economy as critique’, New Political Economy 12(2):261-270.

Sensier, M. and Devine, F. (2017) 'Social Mobility and Brexit' Economics Discussion Paper Series, EDP-1709, Manchester: University of Manchester

Soysal, Y. (2012) 'Citizenship, immigration and the European social project', British Journal of Sociology 63(1):1-21

Swales, K. (2016) Understanding the Leave Vote, London: NatCen

Thompson, E.P. (1971) 'The Moral Economy of the English Crowd', Past and Present 50(Feb):76136.

TUC (2016) Living on the Edge, London: TUC

Wadsworth, J. (2015) Immigration and the UK Labour Market, Paper EA019, London: Centre for Economic Performance (LSE)

Webster, D. (2015) https://www.crimeandjustice.org.uk/resources/benefit-sanctions-britains-secretpenal-system 


\section{Footnotes}

${ }^{1}$ https://www.theguardian.com/politics/2011/jul/01/duncan-smith-appeals-businesses-employ-young$\underline{\text { britons }}$

${ }^{2}$ David Cameron holds the worst house building record since 1923

http://www.independent.co.uk/news/uk/politics/david-cameron-housing-housebuilding-primeminister-england-john-healey-a7144646.html

${ }^{3}$ https://www.gov.uk/government/news/accelerating-action-to-stop-rogue-eu-benefit-claims

${ }^{4}$ An estimated $2 \%$ of total claims

${ }^{5}$ https://www.gov.uk/government/news/accelerating-action-to-stop-rogue-eu-benefit-claims

${ }^{6}$ For a list of changes see

http://www.npi.org.uk/files/7613/7477/4989/Table of changes to welfare.pdf, and

https://www.gov.uk/government/publications/2010-to-2015-government-policy-welfare-reform/2010to-2015-government-policy-welfare-reform

${ }^{7}$ See https://www.channel4.com/news/factcheck/fact-check-43-eu-migrants-claim-benefits

${ }^{8}$ Currently being phased in, to integrate Job Seekers Allowance, Housing Benefit, Working Tax

Credit, Child Tax Credit, Employment Support Allowance (for the disabled), and Income Support (for the economically inactive).

${ }^{9}$ See note 7

${ }^{10}$ Eg differential requirements for participation in the Work Programme.

${ }^{11}$ http://www.entitledto.co.uk/help/Benefit_Changes_April_2016. See also note 6

${ }^{12}$ http://www.telegraph.co.uk/news/uknews/immigration/10995875/David-Cameron-Were-buildingan-immigration-system-that-puts-Britain-first.html

${ }^{13}$ Eg. https://www.gov.uk/government/news/accelerating-action-to-stop-rogue-eu-benefit-claims

${ }^{14}$ See https://www.freemovement.org.uk/brexit-briefing-rights-of-entry-and-residence/

${ }^{15}$ Immigration (European Economic Area) (Amendment) Regulations 2014 (SI 2014/1511) and SI $(2014 / 2761)$

${ }^{16} \mathrm{See} \mathrm{https://www.gov.uk/government/news/accelerating-action-to-stop-rogue-eu-benefit-claims}$ 
https://www.gov.uk/government/news/tough-new-migrant-benefit-rules-come-into-force-tomorrow

${ }^{17}$ http://www.niesr.ac.uk/blog/how-small-small-impact-immigration-uk-wages\#.WFQJTLmQKCk

${ }^{18}$ http://researchbriefings.parliament.uk/ResearchBriefing/Summary/CBP-7445 The main working age benefits are JSA (for unemployment), ESA (for disability) and Income Support (for economically inactive)

${ }^{19}$ https://www.ft.com/content/ac4f8ace-1cf6-11e6-b286-cddde55ca122

${ }^{20}$ https://www.theguardian.com/politics/2016/may/20/reality-check-are-eu-migrants-really-taking$\underline{\text { british-jobs }}$

${ }^{21}$ On perceptions of benefit fraud see http://www.independent.co.uk/news/uk/politics/votersbrainwashed-by-tory-welfare-myths-shows-new-poll-8437872.html, and on migrant access to welfare see https://www.ipsos-mori.com/DownloadPublication/1634_sri-perceptions-and-reality-immigrationreport-2013.pdf chapter 3 .

${ }^{22}$ See https://www.channel4.com/news/factcheck/fact-check-43-eu-migrants-claim-benefits and compare with http://www.dailymail.co.uk/news/article-3467563/886million-eye-watering-sum-paybenefits-work-EU-migrants-just-one-year.html

${ }^{23}$ http://www.niesr.ac.uk/blog/coalition-government\%E2\%80\%99s-record-immigration

${ }^{24}$ https://blogs.ec.europa.eu/ECintheUK/getting-the-facts-straight-eu-rights-to-reside-in-anothermember-state-eu-benefit-claimants-and-nhs-treatment-entitlement/

${ }^{25}$ http://www.migrantsrights.org.uk/blog/2016/06/or-out-eu-it-global-labour-markets-drive-migrationtodays-world

${ }^{26} 53.4 \%$ in England, with Scotland and Northern Ireland supporting Remain (Sensier andDevine, 2017)

${ }^{27}$ An electoral unit of average population 7000, analysed by Becker et al (2016) for four cities

${ }^{28}$ Prior support for the UK Independence Party or the British National Party

${ }^{29}$ https://www.theguardian.com/politics/2016/jun/24/voting-details-show-immigration-fears-wereparadoxical-but-decisive

${ }^{30}$ http://cep.lse.ac.uk/pubs/download/pa015.pdf 
${ }^{31}$ Notably the Scottish vote (62 per cent Remain) displayed a different pattern of response.

${ }^{32}$ http://guardian.newspaperdirect.com/epaper/viewer.aspx

${ }^{33}$ https://www.theguardian.com/politics/2017/nov/01/brexit-vote-cost-niesr-economic-growth

${ }^{34}$ https://www.theguardian.com/business/2017/nov/09/brexit-will-hit-northern-england-economy-hardestippr-north-thinktank 